\title{
Persistence and dissipation behavior of pesticide residues in parsley (Petroselinum crispum) under field conditions
}

\author{
A. Heshmati ${ }^{1}$, H.A. Komaki ${ }^{1}$, F. Nazemi ${ }^{1}$ and A. Mousavi Khaneghah ${ }^{2 *}$ \\ ${ }^{1}$ Department of Nutrition and Food Safety, School of Medicine, Nutrition Health Research Center, Hamadan University \\ of Medical Sciences, Hamadan, Iran; ${ }^{2}$ Department of Food Science, Faculty of Food Engineering, University of Campinas \\ (UNICAMP), Rua Monteiro Lobato, 80. Caixa Postal: 6121.CEP: 13083-862, Campinas, São Paulo, Brazil
}

Corresponding Author: Amin Mousavi Khaneghah, mousavi@unicamp.br

Received: 17 May 2020 / Accepted: 9 July 2020 / Published: 21 July 2020.

(c) 2020 Codon Publications

OPEN ACCESS (c) (i) (을

RESEARCH ARTICLE

\begin{abstract}
The residue level, dissipation behavior, and dietary intake risk of chlorpyrifos-methyl, dimethoate, permethrin, iprodione, metalaxyl, and propargite in parsley (Petroselinum crispum) were investigated under field conditions. Extraction and determination of pesticide residues were carried out by a quick, easy, cheap, effective, rugged, and safe (QuEChERS) method and a gas chromatography/tandem mass spectrometry (GC/MS/MS) system, respectively. Dissipation of chlorpyrifos-methyl, dimethoate, permethrin, iprodione, metalaxyl, and propargite in parsley followed the first-order kinetics with a half-life $\left(\mathrm{t}_{1 / 2}\right)$ of $3.33,3.30,2.94,3.52,4.10$, and 3.38 days, respectively. Based on the dissipation pattern and the maximum residue limits (MRL), preharvest intervals (PHI) of 25, 13, $18,24,1$, and 16 days are suggested for chlorpyrifos-methyl, dimethoate, permethrin, iprodione, metalaxyl, and propargite in parsley, respectively. The estimated daily intake (EDI) of pesticides ranged from 7.37E-05 (dimethoate) to $8.00 \mathrm{E}-04$ (metalaxyl) $\mathrm{mg} / \mathrm{kg}$. The chronic risk assessment showed that the hazard quotient (HQ) was $<1$ and Hazard Index (HI, indicating the cumulative exposure to pesticide residues) was $<100 \%$, demonstrating that an intake of pesticide residues from parsley was safe for humans.
\end{abstract}

Keywords: half-life; parsley; field conditions; post-harvest interval; GC/MS/MS; method validation

\section{Introduction}

Parsley (Petroselinum crispum) with bright green color and a mild, bitter flavor is one of the world's most popular flowering herbs (Charles, 2012; Farzaei et al., 2013). It is mainly cultured as an annual culinary herb in Europe and Western Asia (Charles, 2012). This vegetable is used as a fresh product or a dried spice. It is an excellent source of antioxidants, antibacterial, and antifungal components (Farzaei et al., 2013). The effects of the ingested antioxidant compounds by the consumption of this vegetable on the reduction of cardiovascular disease and some types of cancer have been documented (Brizzolari et al., 2019; Frączek et al., 2019;
Fredotović and Puizina, 2019; Shin et al., 2018). Leaves of parsley had various pharmacological attributes, including anticancer, hepatoprotective, neuroprotective, immunosuppressant, anti-diabetic/coagulant so on, and are used to treat gastrointestinal, disorders, kidney stones, inflammation, amenorrhea, and halitosis (Agyare et al., 2017; Charles, 2012; Farzaei et al., 2013).

The use of pesticides is one of the ways to enhance production efficiency (Badawy et al., 2019; Heshmati et al., 2019; Heshmati and Nazemi, 2018). Pesticides are mixtures of chemical compounds for killing, destroying, or mitigating the threat of pests (Pallarés et al., 2020; Serefoglu and 
Serefoglu, 2016). Although, pesticides prevent or minimize crop loss due to pests, their residues in agricultural products are a major concern with regard to food safety (Aydin and Ulvi, 2019; Hamidi et al., 2019; Nazemi et al., 2016; Shoeibi et al., 2013). In order to maintain human health, pesticide residues in agricultural products and foodstuff should be lower than the maximum residue limit (MRL) set by the legal authority of European Commission (European Commission, 2005; Razzaghi et al., 2018).

As different pests, such as insects and fungi, can grow on parsley (Hershman et al., 1986; Webb, 2006), it is crucial to apply pesticides in order to prevent its yield loss. The occurrence of pesticide residues in parsley has been previously documented (El-Shahawi, 1997; Esturk et al., 2014; Horská et al., 2020; Szpyrka et al., 2015). Quick, easy, cheap, effective, rugged, and safe sample preparation (QuEChERS) method was one of the most important methods for the extraction of pesticide residues from different food products, including parsley samples (Razzaghi et al., 2018). The advantages of the QuEChERS method are the low cost and fast sample preparation, reduced requirements for reagent, and the simultaneous extraction of several pesticide residues (Kolberg et al., 2011; Lehotay et al., 2010). According to previous studies, gas chromatography (GC), gas chromatography/tandem mass spectrometry (GC/MS/MS), or liquid chromatography/tandem mass spectrometry (LC/MS/MS), are the most commonly used methods or techniques to look for pesticide residues in parsley (Esturk et al., 2014; Horská et al., 2020). Chlorpyrifos-methyl, dimethoate, permethrin, iprodione, metalaxyl, and propargite are commonly used in parsley cultivation in Iran and some other countries (Horská et al., 2020). While no information (except on metalaxyl) is available regarding persistence and the waiting periods or pre-harvest interval (PHI) of these pesticide residues in parsley. PHI is number of days between the actual application of a pesticide and when a crop can be harvested such that the pesticide residue level has reached below MRL (Horská et al., 2020). Therefore, dissipation studies will help to determine the waiting periods for these pesticide residues in parsley.

In this regard, this study was aimed to determine the dissipation behavior of insecticides (chlorpyrifos-methyl, dimethoate, and permethrin), fungicides (iprodione and metalaxyl) and acaricides (propargite) in parsley under filed conditions, and to assess their risk for the benefit of parsley consumers.

\section{Materials and methods}

\section{Chemicals and reagents}

The reference substances of chlorpyrifos-methyl, dimethoate, permethrin, iprodione, metalaxyl, and propargite were bought from Dr. Ehrenstorfer Co. (Augsburg, Germany). For spraying of parsley, trade forms of mentioned pesticides were purchased from Mahan Inc. (Tehran, Iran). Acetonitrile, sodium chloride, magnesium sulfate all in the analytical grade were purchased from Merck (Darmstadt, Germany). Supelco (Bellefonte, USA) donated the primary secondary amine (PSA), graphitized carbon black (GCB), perfluorotributylamine (PFTBA), and triphenylmethane (TPM). Other chemicals were of analytical grade and were purchased from Merck (Darmstadt, Germany). TMP was utilized as an internal standard. The mass spectrometer performance was checked daily using PFTBA according to the manufacturer's tuning procedures.

\section{Field experiments}

The field experiment was conducted in September of 2018 in Hamadan, Iran. Parsley was cultivated in several separate plots. Each plot had an area of $16 \mathrm{~m}^{2}$ and was sprayed with one type of pesticide using a portable sprayer (Ronix, Model: RH-6005, Tehran, Iran) with standard flat-fan nozzles and a water volume of $12 \mathrm{~L}$. Chlorpyrifos-methyl (Dursban 40.8\% water emulsifiable concentrates or EC), dimethoate (Roxion 40\% EC), permethrin (Ambush 10\% EC), iprodione (52.5\% wettable powder or WP), metalaxyl (Ridomil 5 granule or GR), and propargite (Omite 57\% water-based emulsion or EW) were separately applied to three test plots at the recommended dosages of 400, 816, $100,525,100$, and $570 \mathrm{~g}$ of active ingredient per hectare (g.a.i./ha), respectively. During the culturing of parsley and the field trial, no rain was reported, and the mean daily temperature, air humidity, and wind speed were $22^{\circ} \mathrm{C}, 32 \%$, and $10 \mathrm{~km} / \mathrm{h}$, respectively. Parsley samples were collected at $2 \mathrm{~h}$, and after 2, 4, 6, 10,15, and 20 days after spraying. During sampling, approximately $1.5 \mathrm{~kg}$ of parsley was collected from each plot and transferred to the laboratory. After the addition of dry ice to parsley samples, they were ground with a mill (Romer mill, Stylemaster Drive, USA). Fifty grams of milled samples were weighted and utilized for pesticide residue analysis.

\section{Extraction of pesticide residues}

To extract pesticide residue from the parsley sample, the QuEChERS method was applied (Badawy et al., 2020; Heshmati et al., 2019; Hua et al., 2019) according to Figure 1.

\section{Apparatus and chromatographic conditions}

A GC/MS/MS (model 7000C, Agilent, Santa Clara, CA, USA) equipped with an autosampler (model Agilent 7693, Agilent, Santa Clara, CA, USA) and an HP-5 capillary column $(30 \mathrm{~m} \times 0.25 \mathrm{~mm}$ I.D., $0.25 \mu \mathrm{m}$ film 
thicknesses) was used to determine pesticide residue concentration. The oven temperature was programmed as follows: the initial temperature was $75^{\circ} \mathrm{C}$, then it was increased to $120^{\circ} \mathrm{C}$ with a $25^{\circ} \mathrm{C} / \mathrm{min}$ ramp, afterward it was increased to $300^{\circ} \mathrm{C}$ with a $5^{\circ} \mathrm{C} / \mathrm{min}$ ramp, and this temperature was maintained for $11 \mathrm{~min}$. The helium (purity of 99.99\%) was utilized as carrier gas (He) with a flow rate of $1 \mathrm{~mL} / \mathrm{min}$. Other conditions of tandem mass spectrometer include the injector temperature, $250^{\circ} \mathrm{C}$; the quadrupole temperature, $150^{\circ} \mathrm{C}$; and the ion source temperature, $230^{\circ} \mathrm{C}$; and ionization energy, $70 \mathrm{eV}$. The mass spectrometer was operated in the electron ionization (EI) mode and involved multi-reaction monitoring (MRM), while a GC/MS/MS injector was used in the splitless mode. The optimized GC/MS/MS parameters are shown in Table 1.

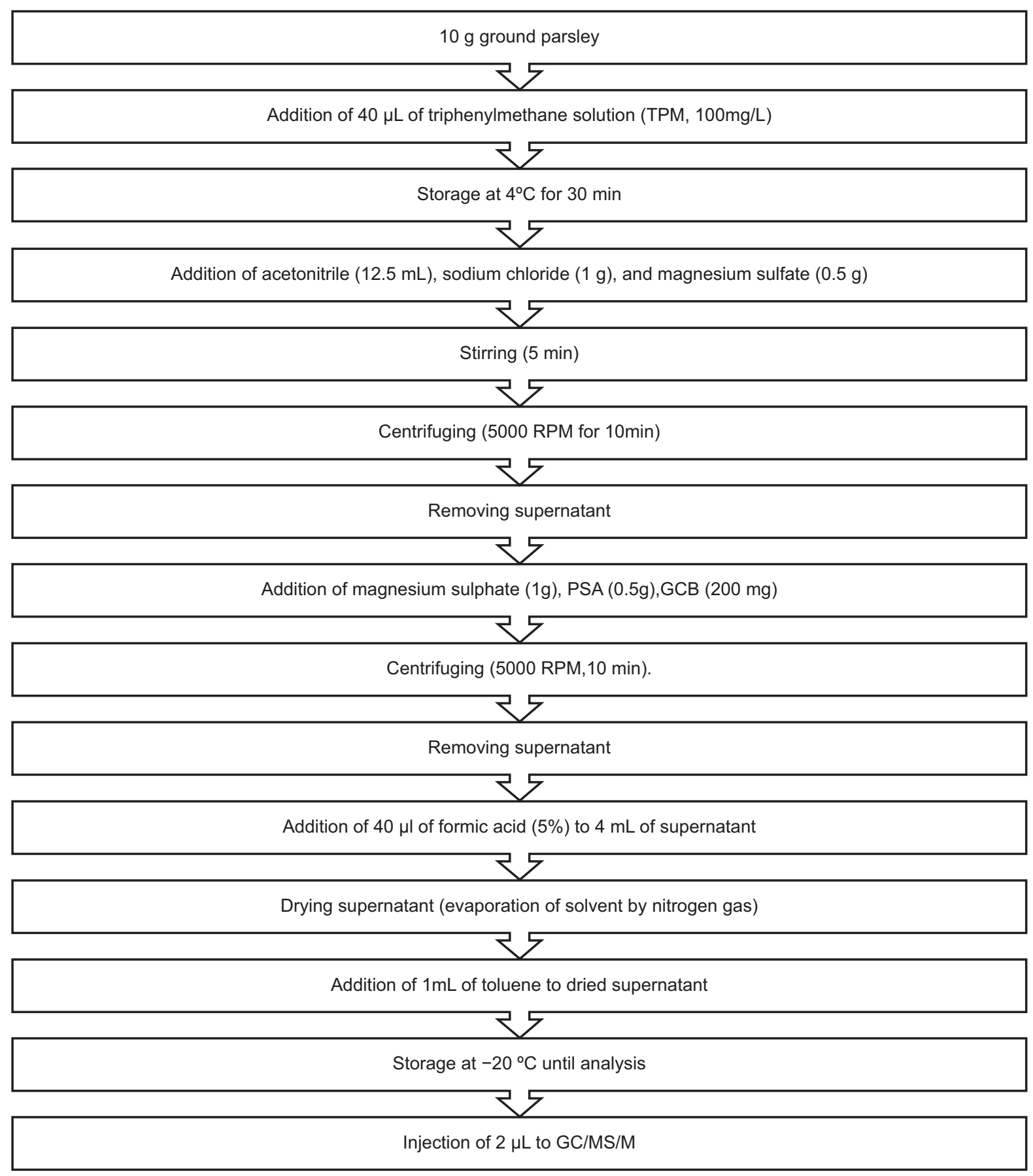

Figure 1. The diagram of QuEChERS method used for the extraction of pesticide. 


\section{Method validation}

For method validation, linearity, recovery, the limit of detection (LOD), and the limit of quantification (LOQ) were determined. External calibration curves, along with matrix-matched methods, were performed for pesticide residues in the concentration of $0.005-0.400 \mathrm{mg} / \mathrm{kg}$. To assess the accuracy and precision of the analysis method, the recovery experiments were performed. For recovery, blank parsley samples were fortified with $0.005,0.010$, and $0.020 \mathrm{mg} / \mathrm{kg}$ of a standard solution of each pesticide. Then, the pesticide residue of spiked samples was extracted and measured following the above procedures. At each fortification level, five replicates were carried out. This experiment was repeated three consecutive days to obtain test precision. Recovery was calculated from the dividing of found pesticide content in spiked samples to real content. LOD and LOQ were considered as signal-to-noise ratio $(\mathrm{S} / \mathrm{N})$ of 3:1 and 10:1, respectively (Maznah et al., 2018).

\section{Risk assessment}

For long-term risk assessment, the estimated daily intake (EDI), HQ (Hazard Quotient), and Hazard Index (HI) were determined according to the following equations (Cámara et al., 2020; Gui et al., 2019; Milinčić et al., 2020; Pallarés et al., 2020; Tandon, 2016; Yang et al., 2020).

$\operatorname{EDI}(\mathrm{mg} / \mathrm{kg}$ bw $/$ day $)=\frac{\operatorname{STMR}(\mathrm{mg} / \mathrm{kg}) \times \mathrm{FI}(\mathrm{kg} / \text { day })}{\mathrm{bw}(\mathrm{kg})}$

(Equation 1)

$$
\mathrm{HQ}=\frac{\mathrm{EDI}}{\mathrm{ADI}} \times 100 \% \quad \text { (Equation 2) }
$$

$$
\mathrm{HI}=\sum \mathrm{HQ} \quad \text { (Equation 3) }
$$

supervised trials median residue (STMR) ( $\mathrm{mg} / \mathrm{kg}$ ), FI (food intake, $\mathrm{kg} /$ day), bw (body weight, $\mathrm{kg}$ ), and the accepted daily intake (ADI) (mg/kg bw/day) indicated the supervised trials' median residue (Dong et al., 2017), daily per capita consumption of parsley $(58 \mathrm{~g})$ in Iran (Heshmati et al., 2020a; ISIRI, 2010; Mehri et al., 2019), the bodyweight of adults $(70 \mathrm{~kg})$, and the ADI, respectively. The STMR is the median of pesticide residues' level in the edible portion of a food substance applied in supervised trials according to maximum good agricultural practice (GAP) conditions (FAO, 2002). HI was the cumulative exposure to pesticide residues, which is estimated by summing HQ of each pesticide residue. If $\mathrm{HI}$ exceeds $100 \%$, the risk is not acceptable (Cámara et al., 2020; Milinčić et al., 2020; Yang et al., 2020).

\section{Statistical analysis}

To determine the degradation kinetics of each pesticide, its residue level versus time was plotted, and the maximum $R^{2}$ (the squared correlation coefficients) for different curves was determined to obtain the best curve for degradation kinetics. The degradation of whole pesticides followed first-order rate equation, that is, $\mathrm{C}_{\mathrm{t}}=\mathrm{C}_{0} \mathrm{e}^{-\mathrm{kt}}$, where $\mathrm{C}_{0}$ and $\mathrm{C}_{\mathrm{t}}$, indicated the level of the pesticide residues after $2 \mathrm{~h}$ of spraying on day $t$, while $\mathrm{K}$ and $\mathrm{t}$ are the degradation rate constant and time, respectively (Galietta et al., 2010). The $\mathrm{t}_{1 / 2}$ (necessary time for the reduction of pesticide residues' concentration to $50 \%$ of its initial level) and PHI were determined with the following equations (Chen et al., 2016):

$$
\mathrm{t}_{1 / 2}=\frac{\ln 2}{\mathrm{k}} \quad \text { (Equation 3) }
$$

$$
\mathrm{PHI}=\frac{\ln \left(\mathrm{MRL} \text { of pesticide } / \mathrm{C}_{0}\right)}{-\mathrm{k}}(\text { Equation } 4)
$$

\begin{tabular}{|c|c|c|c|c|c|c|}
\hline Name of pesticide & Retention time & $\begin{array}{l}\text { Diagnostic } \\
\text { ions }\end{array}$ & Quantification ion & $\begin{array}{c}\text { Collision } \\
\text { energy } \\
(\mathrm{eV})\end{array}$ & $\begin{array}{l}\text { Product ion } \\
\qquad(\mathrm{m} / \mathrm{z})\end{array}$ & $\begin{array}{l}\text { Parent ion } \\
\quad(\mathrm{m} / \mathrm{z})\end{array}$ \\
\hline Chlorpyrifos-methyl & 30.04 & $\begin{array}{c}314 \text { (545), } 257.8,197 \text { (999), } \\
199(956)\end{array}$ & 314 & 10 & 168.9 & 196.8 \\
\hline Dimethoate & 16.901 & 86.9 (999), 93 (618), $124.8(502)$ & 124.8 & 5 & 198.9 & 203 \\
\hline Permethrin & 33.930 & $\begin{array}{c}183.0 \text { (999), } 164.9(172), 162.9 \\
(204)\end{array}$ & 183.0 & 10 & 149 & 391 \\
\hline Iprodion & 29.860 & $\begin{array}{c}186.8(570), 313.9(965), 243.7 \\
(150)\end{array}$ & 186.8 & 10 & 245 & 313 \\
\hline Metalaxyl & 20.710 & $\begin{array}{c}206.1 \text { (999), } 159.9 \text { (650), } 132.0 \\
\text { (649), } 249.0(499)\end{array}$ & 206.1 & 10 & 117 & 132 \\
\hline Propargite & 29.113 & $\begin{array}{c}350.2(20), 201(150), 134.9 \\
\text { (999), } 173(252)\end{array}$ & 350.2 & 15 & 107.1 & 134.8 \\
\hline
\end{tabular}

$\mathrm{K}$ and $\mathrm{t}$ are the degradation rate constant and time, respectively.

Table 1. The retention time, diagnostic ions, and the selected quantification ion for the pesticide residue analysis. 
MRL of chlorpyrifos-methyl, dimethoate, permethrin, iprodione, metalaxyl, and propargite in parsley was considered as 0.02, 0.02, 0.05, 0.02, 3, and $0.02 \mathrm{mg} / \mathrm{kg}$, respectively (Commission Regulation, 2017a, 2017b, 2017c, 2018a, 2018b, 2019).

\section{Results and discussion}

\section{Method validation}

The data of method validation is presented in Table 2 . The recovery range of chlorpyrifos-methyl, dimethoate, permethrin, iprodione, metalaxyl, and propargite was 99.02-102.71, 92.73-98.53, 98.53-114.98, 90.69-98.37, 93.15-98.90, and 94.36-104.06\%, respectively.

The LOD for chlorpyrifos-methyl, dimethoate, permethrin, iprodione, metalaxyl, and propargite was 1.78 , $0.12,3.82,1.11,1.35$, and $2.44 \mu \mathrm{g} / \mathrm{kg}$, respectively. The LOQ values obtained for pesticides were lower than their MRL, and coefficients of determination $\left(R^{2}\right)$ of the calibration curve were $>0.999$. Therefore, the established method was suitable and satisfactory for analysis.

\section{The dissipation of chlorpyrifos-methyl, dimethoate, permethrin, iprodione, metalaxyl, and propargite in parsley}

The dissipation curves of chlorpyrifos-methyl, dimethoate, permethrin, iprodione, metalaxyl, and propargite under field conditions are presented in Figure 2. Two hours after pesticide application, the initial deposits of chlorpyrifos-methyl, dimethoate, permethrin, iprodione, metalaxyl, and propargite were 4.748, 0.259, 2.757, 2.098, 3.348 and $0.474 \mathrm{mg} / \mathrm{kg}$, respectively. The data regarding the dissipation behavior of the analyzed pesticide in parsley, such as kinetic equation, half-lives, and $R^{2}$,are given in Table 3. Half-life values for chlorpyrifos-methyl, dimethoate, permethrin, iprodione, metalaxyl, and propargite were $3.33,3.30,2.94,3.52,4.10$, and 3.38 days, respectively. The highest PHI (25 days) was related to chlorpyrifos-methyl, while metalaxyl had the lowest PHI ( 1 day). After 28 days in field conditions, residue levels of chlorpyrifos-methyl, dimethoate, permethrin, iprodione, metalaxyl, and propargite decreased to 98.59, 98.46, $99.20,98.33,95.31$, and $98.31 \%$, respectively.

The dissipation pattern of dimethoate in other crops was partly different from our findings. In papaya and guava, $\mathrm{t}_{1 / 2}$ of dimethoate was reported as 3.07-5.04 and 2.8-3.3 days; both these findings were similar to our results, while $t_{1 / 2}$ of this pesticide in chili fruits (1.94 days) and mango ( 2 days) was lower than the findings (3.30 days) of the present study (Ahuja et al., 2005; Bhattacherjee and

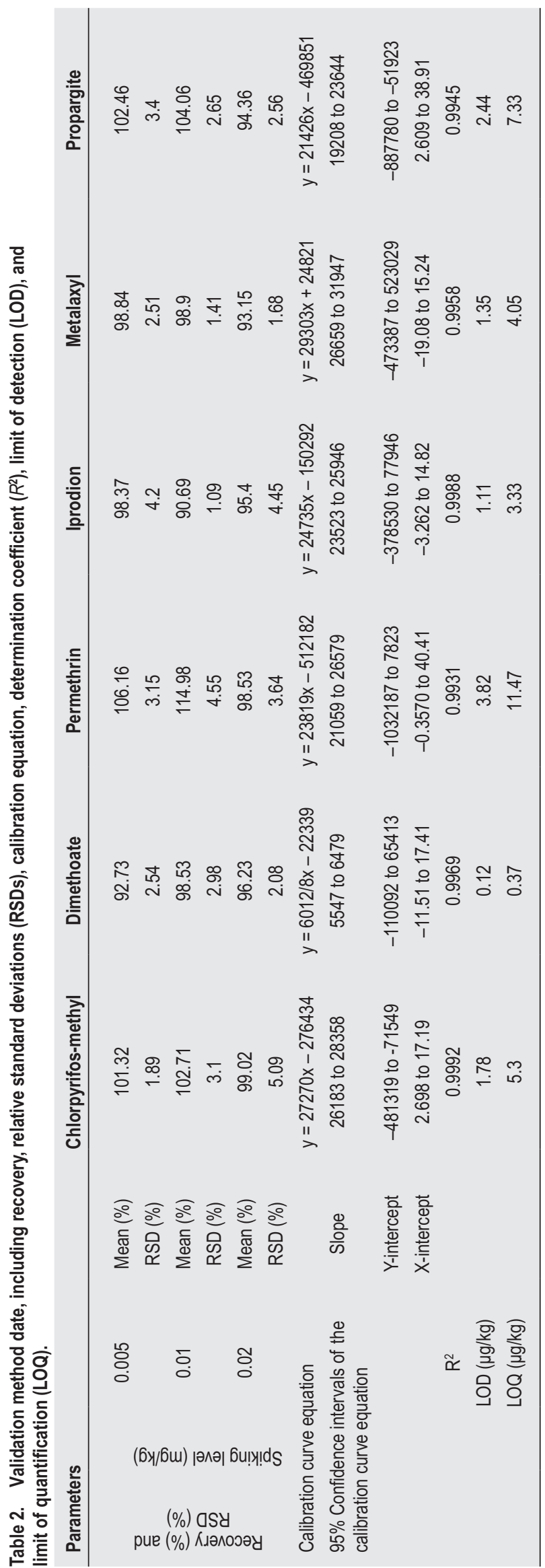


Dikshit, 2016; Khan et al., 2009; Varghese et al., 2011). The half-life of dimethoate in our study (3.30 days) was lower than that reported for chilly (4.7 days) and okra (5.21 days) (Waghulde et al., 2011). The PHI of dimethoate in parsley (132 days) was higher than that in papaya (3-5 days), guava (3 days), and mango (6-7 days), while it was lower than that in chili (13.63 days) and pomegranate (31.5 days at the standard dose of application and 43.0 days at a double dose of application) (Ahuja et al., 2005; Bhattacherjee and Dikshit, 2016; Khan et al., 2009; Utture et al., 2012; Varghese et al., 2011).

The half-life (3.33 days) and PHI (25 days) for chlorpyrifos obtained in this study were longer than those reported for green mustard $\left(\mathrm{t}_{1 / 2}: 1.1-1.5\right.$ days and PHI: 4 days) (Chai et al., 2009). In other studies dependent on chlorpyrifos formulates, its $t_{1 / 2}$ in orange, peach, tomato, table grape, and wine grape was 8-13, 9.1-14, 6.9-9.1, 7.7-13.9, and 6.6-13.3 days, respectively (Angioni et al., 2011).
The dissipation of metalaxyl has previously been investigated (Chen et al., 2010; Liu et al., 2012; Malhat, 2017; Ramezani and Shahriari, 2015; Rattan and Sharma, 2012). The $t_{1 / 2}$ of this pesticide on watermelon, tomato, and cucumber was reported as 3.2-3.5, 1.18, and 3-35 days, respectively. While these findings were lower than that of the current study (4.10 days) (Chen et al., 2010; Malhat, 2017; Rattan and Sharma, 2012); a higher $t_{1 / 2}$ (4.9 days) was reported for grape samples (Liu et al., 2012). The calculated waiting period of 1 day for the safe consumption of parsley sprayed with metalaxyl in the current study was similar to corresponding values for cucumber (Ramezani and Shahriari, 2015; Rattan and Sharma, 2012). However, Malhat (2017) reported longer waiting periods (7 days) for tomato (Malhat, 2017). The PHI of pesticides had correlations with their MRL (Heshmati et al., 2020b). A shorter PHI of metalaxyl in parsley was related to greater MRL (3 mg/kg) of this pesticide in comparison with another pesticide.
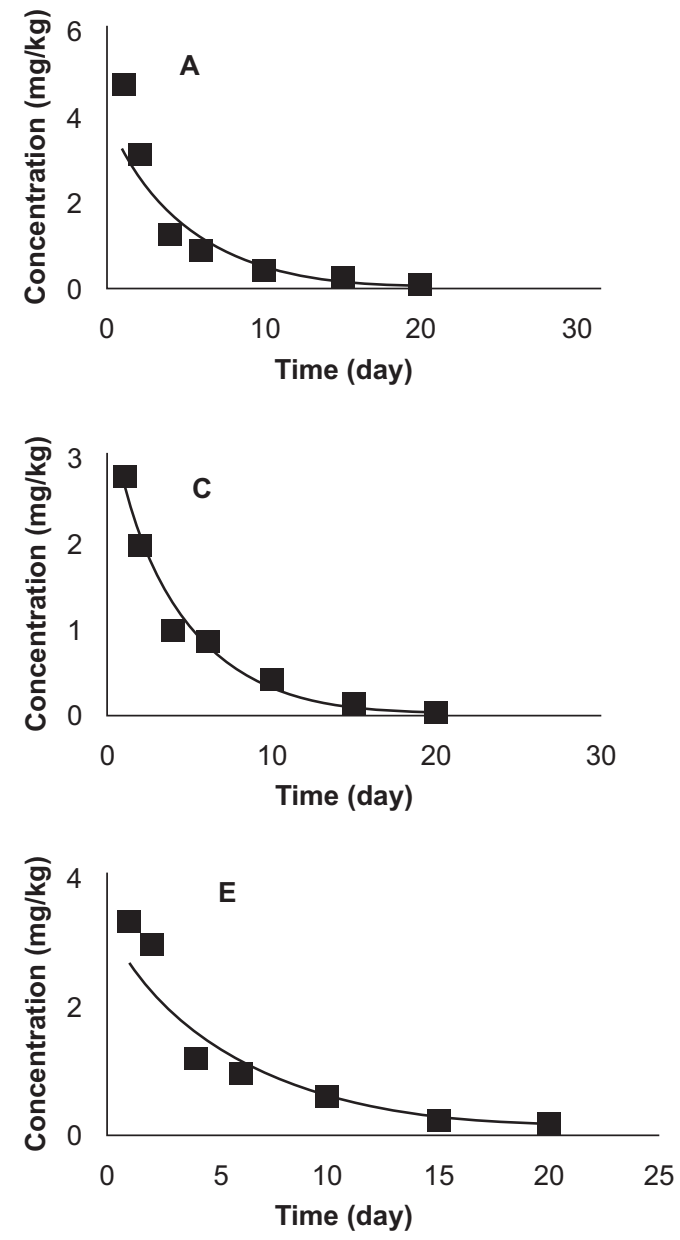
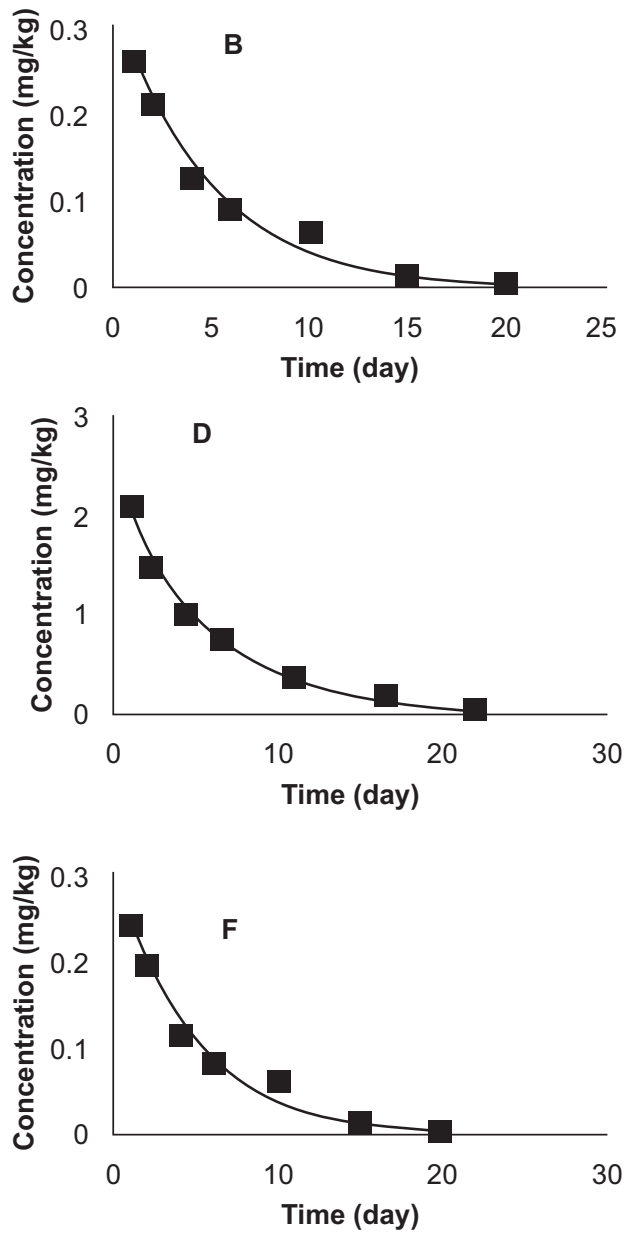

Figure 2. Dissipation of A: chlorpyrifos methyl, B: dimethoate, C: permethrin, D: iprodione, E: metalaxyl, and F: propargite in parsley under field conditions. 
Table 3. The initial deposits $(\mathrm{mg} / \mathrm{kg})$, regression equation, $R^{2}$, half-life $\left(\mathrm{t}_{1 / 2}\right)$, and preharvest intervals (PHI) of pesticides in parsley.

\begin{tabular}{lcccccc} 
& Chlorpyrifos-methyl & Dimethoate & Permethrin & Iprodione & Metalaxyl & Propargite \\
\hline $\begin{array}{l}\text { Initial deposits } \\
\text { (mg/kg) }\end{array}$ & 4.748 & 0.259 & 2.757 & 2.098 & 3.348 & 0.474 \\
$\begin{array}{l}\text { Regression } \\
\text { equation }\end{array}$ & $\mathrm{y}=4.0061 \mathrm{e}^{-0.208 x}$ & $\mathrm{y}=0.3347 \mathrm{e}^{-0.21}$ & $\mathrm{y}=3.3444 \mathrm{e}^{-0.2367 x}$ & $\mathrm{y}=2.4335 \mathrm{e}^{-0.197 x}$ & $\mathrm{y}=3.455 \mathrm{e}^{-0.1694 x}$ & $\mathrm{y}=0.5031 \mathrm{e}^{-0.205 x}$ \\
$R^{2}$ & & & & & & \\
$\mathrm{t}_{1 / 2}$ (day) & 0.9675 & 0.97683 & 0.9801 & 0.9763 & 0.968 & 0.9776 \\
$\mathrm{PHI}$ (day) & 3.33 & 3.30 & 2.94 & 3.52 & 4.10 & 3.38 \\
\hline
\end{tabular}

Propargite is an effective acaricide, which is utilized for a large number of crops (Kumar et al., 2005). The halflife of propargite in green tea leaves, apple, and Brinjal Fruits was, respectively, 1.79, 2.61, 6.2-10m and 3.073.54 days (Kang et al., 2009; Kumar et al., 2005; Lou et al., 2008), while $t_{1 / 2}$ of this pesticide in our study was 3.38 days. In the current study, we found that a waiting period of 16 days was needed for the safe consumption of parsley to prevent any health hazards due to propargite, while shorter waiting periods were advised for other crops, such as 1 day for the brinjal fruit (Kang et al., 2009).

The half-life of iprodione in our study (3.52 days) was shorter than that in tomato (6.8 days) and similar to that in sweet cherry (3.47 days) (Lazić et al., 2016; Omirou et al., 2009). The occurrence of permethrin was reported for some vegetables, although little published information was found regarding its $t_{1 / 2}$ and PHI (George, 1985).

The reasons for discrepancies of $\mathrm{t}_{1 / 2}$ and PHI values in our study when compared with previous studies were related to the differences in effective factors on pesticide dissipation. The dissipation pattern of pesticides depended on pesticide formulations and physical-chemical properties (vapor pressure and solubility), climate conditions (temperature, humidity, sunlight), plant characteristics (genus and species), location of application of the pesticide, and the number and dosage of pesticide applications (Chai et al., 2009; Heshmati et al., 2020b; Jacobsen et al., 2015; Kumar et al., 2005). Therefore, the variations in these factors in various studies resulted in different $t_{1 / 2}$ and PHI values being obtained and reported for each pesticide.

\section{Risk assessment}

The findings of risk assessment are summarized in Table 4. STMR for chlorpyrifos-methyl, dimethoate, permethrin, iprodione, metalaxyl, and propargite were $0.876,0.089,0.851,0.750,0.965$, and $0.166 \mathrm{mg} / \mathrm{kg}$, respectively. In a previous study, the estimated STMR of chlorpyrifos in rice and cabbage, respectively, was 0.01 and $0.227 \mathrm{mg} / \mathrm{kg}$ (Chen et al., 2012), which was lower than our findings. As shown, the pesticide EDI ranged from 7.37E-05 (dimethoate) to 8.00E-04 (Metalaxyl) mg/ $\mathrm{kg}$ bw/day, and HQ of all them were $<100 \%$. HI of six pesticides was lower than $100 \%$, and this finding is similar to previous studies (Cámara et al., 2020; Milinčić et al., 2020; Yang et al., 2020). Overall, these results showed that for the recommended dose of pesticide, the long-term exposure of consumers to dimethoate,

Table 4. Dietary intake risk assessments of dimethoate, chlorpyrifos methyl, permethrin, iprodione, metalaxyl, and propargite through parsley consumption.

\begin{tabular}{lcccc} 
Pesticide & STMR $(\mathrm{mg} / \mathrm{kg})$ & EDI $(\mathrm{mg} / \mathrm{kg}$ bw/day $)$ & ADI (mg/kg bw/day) & HQ (\%) \\
\hline Chlorpyrifos-methyl & 0.876 & $7.26 \mathrm{E}-04$ & 0.010 & 7.26 \\
Dimethoate & 0.089 & $7.37 \mathrm{E}-05$ & 0.002 & 3.69 \\
Permethrin & 0.851 & $7.05 \mathrm{E}-04$ & 0.050 & 1.41 \\
Iprodione & 0.750 & $6.21 \mathrm{E}-04$ & 0.020 & 3.11 \\
Metalaxyl & 0.965 & $8.00 \mathrm{E}-04$ & 0.050 & 1.60 \\
Propargite & 0.166 & $1.38 \mathrm{E}-04$ & 0.030 & 0.46 \\
& & & & $\mathrm{HI}=17.52$ \\
\hline
\end{tabular}

HQ: Hazard Quotient; HI, Hazard Index; ADI, accepted daily intake; STMR. 
chlorpyrifos-methyl, permethrin, iprodione, metalaxyl, and propargite residues through parsley consumption is relatively negligible. However, it's necessary to calculate EDI of mentioned pesticide through other crop consumption on which these pesticides may be used.

\section{Conclusion}

This study is the first report on dissipation behavior and dietary intake risk of chlorpyrifos-methyl, dimethoate, permethrin, iprodione, metalaxyl, and propargite in parsley (Petroselinum crispum) under the field conditions. Dissipation of chlorpyrifos-methyl, dimethoate, permethrin, iprodione, metalaxyl, and propargite in parsley followed the first-order kinetics with $\mathrm{t}_{1 / 2}$ of 3.33 , $3.30,2.94,3.52,4.10$, and 3.38, respectively. Based on the dissipation pattern and MRL, PHI of 25, 13, 18, 24, 1, and 16 days are suggested for chlorpyrifos-methyl, dimethoate, permethrin, iprodione, metalaxyl, and propargite in parsley, respectively. The risk assessment showed HQ was $<1$ for spraying the mentioned pesticide on parsley, and therefore, they were safe for humans. Finally, the results of the current study would be used as a reference for establishing PHI of chlorpyrifos-methyl, dimethoate, permethrin, iprodione, metalaxyl, and propargite in parsley to provide guidance on the safe and proper use of these pesticides. However, the current investigation was devoted to assessing the EDI of pesticides through parsley consumption. It is, however, necessary to calculate EDI of mentioned pesticides through the consumption of other crops.

\section{Acknowledgment}

The authors would like to thank Hamadan University of Medical Science (Project No: 9706203689).

\section{Conflict of interest}

No potential conflict of interest was reported by the authors.

\section{References}

Agyare, C., Appiah, T., Boakye, Y.D. and Apenteng, J.A., 2017. Chapter 25 - Petroselinum crispum: a review. In: V. Kuete (Ed.), Medicinal Spices and Vegetables from Africa. Academic Press, Cambridge, MA, pp. 527-547. http://dx.doi.org/10.1016/ B978-0-12-809286-6.00025-X

Ahuja, A., Mohapatra, S. and Awasthi, M., 2005. Persistence and dissipation of dimethoate and dicofol residues in/on papaya. Pest Management In Horticultural Ecosystems 11: 39-43.
Angioni, A., Dedola, F., Garau, A., Sarais, G., Cabras, P. and Caboni, P., 2011. Chlorpyrifos residues levels in fruits and vegetables after field treatment. Journal of Environmental Science and Health, Part B 46: 544-549. http://dx.doi.org/10.1080/0360 1234.2011.583880

Aydin, S. and Ulvi, M., 2019. Residue levels of pesticides in nuts and risk assessment for consumers. Quality Assurance and Safety of Crops \& Foods 11: 539-548. http://dx.doi.org/10.3920/ QAS2018.1405

Badawy, M.E.I., Ismail, A.M.E. and Ibrahim, A.I.H., 2019. Quantitative analysis of acetamiprid and imidacloprid residues in tomato fruits under greenhouse conditions. Journal of Environmental Science and Health, Part B 54: 898-905. http:// dx.doi.org/10.1080/03601234.2019.1641389

Badawy, M.E.I., Mahmoud, M.S. and Khattab, M.M., 2020. Residues and dissipation kinetic of abamectin, chlorfenapyr and pyridaben acaricides in green beans (Phaseolus vulgaris L.) under field conditions using QuEChERS method and HPLC. Journal of Environmental Science and Health, Part B 55:1-8. http://dx. doi. org/10.1080/03601234.2020.1726701

Bhattacherjee, A. and Dikshit, A., 2016. Dissipation kinetics and risk assessment of thiamethoxam and dimethoate in mango. Environmental Monitoring and Assessment 188: 165. http://dx. doi.org/10.1007/s10661-016-5160-3

Brizzolari, A., Brandolini, A., Glorio-Paulet, P. and Hidalgo, A., 2019. Antioxidant capacity and heat damage of powder products from South American plants with functional properties. Italian Journal of Food Science 31: 731-748. https://doi.org/10.14674/ IJFS-1521

Cámara, M., Cermeño, S., Martínez, G. and Oliva, J., 2020. Removal residues of pesticides in apricot, peach and orange processed and dietary exposure assessment. Food Chemistry 325:126936. http://dx.doi.org/10.1016/j.foodchem.2020.126936

Chai, L.K., Mohd-Tahir, N. and Bruun Hansen, H.C., 2009. Dissipation of acephate, chlorpyrifos, cypermethrin and their metabolites in a humid-tropical vegetable production system. Pest Management Science 65:189-196. http://dx.doi. org/10.1002/ps.1667

Charles, D., 2012. Parsley. In Handbook of Herbs and Spices. Elsevier, Woodhead Publishing, Sawston, Cambridge, pp. 430-451.

Chen, C., Qian, Y., Liu, X., Tao, C., Liang, Y. and Li, Y., 2012. Risk assessment of chlorpyrifos on rice and cabbage in China. Regulatory Toxicology and Pharmacology 62: 125-130. http:// dx.doi.org/10.1016/j.yrtph.2011.12.011

Chen, L., Jia, C., Zhu, X., He, M., Yu, P. and Zhao, E., 2010. Residual dynamic analysis of metalaxyl-M in watermelon and soil. Agrochemicals 49: 282-283.

Chen, W., Liu, Y. and Jiao, B., 2016. Dissipation behavior of five organophosphorus pesticides in kumquat sample during honeyed kumquat candied fruit processing. Food Control 66: 87-92. http://dx.doi.org/10.1016/j.foodcont.2016.01.033

Commission Regulation, 2017a. (EU) 2017/623 amending Annexes II and III to Regulation (EC) No 396/2005 of the European Parliament and of the Council as regards maximum residue levels for acequinocyl, amitraz, coumaphos, diflufenican, flumequine, metribuzin, permethrin, pyraclostrobin and 
streptomycin in or on certain products. Official Journal of the European Union L 93/1.

Commission Regulation, 2017b. (EU) 2017/1135 amending Annexes II and III to Regulation (EC) No 396/2005 of the European Parliament and of the Council as regards maximum residue levels for dimethoate and omethoate in or on certain products Official Journal of the European Union L 164/28.

Commission Regulation, 2017c. (EU) 2017/1164 amending Annexes II and III to Regulation (EC) No 396/2005 of the European Parliament and of the Council as regards maximum residue levels for acrinathrin, metalaxyl and thiabendazole in or on certain products. Official Journal of the European Union L 170/3.

Commission Regulation, 2018a. (EU) 2018/686 amending Annexes II and III to Regulation (EC) No 396/2005 of the European Parliament and of the Council as regards maximum residue levels for chlorpyrifos, chlorpyrifos-methyl and triclopyr in or on certain products. Official Journal of the European Union L 121/30.

Commission Regulation, 2018b. (EU) 2018/832 amending Annexes II, III and V to Regulation (EC) No 396/2005 of the European Parliament and of the Council as regards maximum residue levels for cyantraniliprole, cymoxanil, deltamethrin, difenoconazole, fenamidone, flubendiamide, fluopicolide, folpet, fosetyl, mandestrobin, mepiquat, metazachlor, propamocarb, propargite, pyrimethanil, sulfoxaflor and trifloxystrobin in or on certain products/. Official Journal of the European Union L $140 / 38$.

Commission Regulation, 2019. (EU) 2019/38 amending Annexes II and V to Regulation (EC) No 396/2005 of the European Parliament and of the Council as regards maximum residue levels for iprodione in or on certain products. Official Journal of the European Union: L 9/94.

Dong, B., Shao, X., Lin, H. and Hu, J., 2017. Dissipation, residues and risk assessment of metaldehyde and niclosamide ethanolamine in pakchoi after field application. Food Chemistry 229: 604-609. http://dx.doi.org/10.1016/j.foodchem.2017.02.117

El-Shahawi, M., 1997. Retention profiles of some commercial pesticides, pyrethroid and acaricide residues and their application to tomato and parsley plants. Journal of Chromatography A 760: 179-192. http://dx.doi.org/10.1016/S0021-9673(96)00872-2

Esturk, O., Yakar, Y. and Ayhan, Z., 2014. Pesticide residue analysis in parsley, lettuce and spinach by LC-MS/MS. Journal of Food Science and Technology 51: 458-466. http://dx.doi.org/10.1007/ s13197-011-0531-9

European Commission, 2005. Regulation (EC) No 396/2005 of the european parliament and of the council of 23 february 2005 on maximum residue levels of pesticides in or on food and feed of plant and animal origin and amending council directive 91/414/ EEC. Access to the Official Journal 50: 1-50.

FAO (Food and Agriculture Organization), 2002. JMPR Practices in Estimation of Maximum Residue Levels, and Residues Levels for Calculation of Dietary Intake of Pesticide Residues Submission and Evaluation of Pesticide Residues data for the Estimation of Maximum Residue Levels in Food and Feed. FAO. Rome, Italy.

Farzaei, M.H., Abbasabadi, Z., Ardekani, M.R.S., Rahimi, R. and Farzaei, F., 2013. Parsley: a review of ethnopharmacology, phytochemistry and biological activities. Journal of Traditional
Chinese Medicine 33: 815-826. http://dx.doi.org/10.1016/ S0254-6272(14)60018-2

Frączek, B., Morawska, M., Gacek, M. and Pogoń, K., 2019. Antioxidant activity as well as vitamin $\mathrm{C}$ and polyphenol content in the diet for athletes. Italian Journal of Food Science 31: 617-630. https://doi.org/10.14674/IJFS-1510

Fredotović, Ž. and Puizina, J., 2019. Edible allium species: chemical composition, biological activity and health effects. Italian Journal of Food Science 31: 19-39. https://doi.org/10.14674/ IJFS-1221

Galietta, G., Egaña, E., Gemelli, F., Maeso, D., Casco, N., Conde, P. and Nuñez, S., 2010. Pesticide dissipation curves in peach, pear and tomato crops in Uruguay". Journal of Environmental Science and Health, Part B 46: 35-40. http://dx.doi.org/10.1080/ 03601234.2010.515504

George, D.A., 1985. Permethrin and its two metabolite residues in seven agricultural crops. Journal - Association of Official Analytical Chemists 68: 1160-1163. http://dx.doi.org/10.1093/ jaoac/68.6.1160

Gui, T., Jia, G.F., Xu, J., Ge, S.J., Long, X.F., Zhang, Y.P. and Hu, D.Y., 2019. Determination of the residue dynamics and dietary risk of thiamethoxam and its metabolite clothianidin in citrus and soil by LC-MS/MS. Journal of Environmental Science and Health, Part B 54: 326-335. http://dx.doi.org/10.1080/03601234.2019.1 571361

Hamidi, M., Nili-Ahmadabadi, A. and Heshmati, A., 2019. Evaluation of different preparation methods of edible mushroom (Agaricus bisporus, strains H737) on reduction of health hazards caused by deltamethrin residue. Iranian Journal of Nutrition Sciences \& Food Technology 14: 95-104.

Hershman, D., Varney, E. and Johnston, S., 1986. Etiology of parsley damping-off and influence of temperature on disease development. Plant Disease 70: 927-930. http://dx.doi.org/10.1094/ PD-70-927

Heshmati, A., Hamidi, M. and Nili-Ahmadabadi, A., 2019. Effect of storage, washing, and cooking on the stability of five pesticides in edible fungi of Agaricus bisporus: a degradation kinetic study. Food Science \& Nutrition 7: 3993-4000. http://dx.doi. org/10.1002/fsn3.1261

Heshmati, A., Mehri, F., Karami-Momtaz, J. and Khaneghah, A.M., 2020a. Concentration and risk assessment of potentially toxic elements, lead and cadmium, in vegetables and cereals consumed in Western Iran. Journal of Food Protection 83: 101-107. http://dx.doi.org/10.4315/0362-028X.JFP-19-312

Heshmati, A. and Nazemi, F., 2018. Dichlorvos (DDVP) residue removal from tomato by washing with tap and ozone water, a commercial detergent solution and ultrasonic cleaner. Food Science and Technology 38: 441-446. https://doi. org/10.1590/1678-457x.07617

Heshmati, A., Nili-Ahmadabadi, A., Rahimi, A., Aliasghar, V. and Taheri, M., 2020b. Dissipation behavior and risk assessment of fungicide and insecticide residues in grape under open-field, storage and washing conditions. Journal of Cleaner Production 270:122287. http://dx.doi.org/10.1016/j.jclepro.2020.122287

Horská, T., Kocourek, F., Stará, J., Holý, K., Mráz, P., Krátký, F., Kocourek, V. and Hajšlová, J., 2020. Evaluation of pesticide 
residue dynamics in lettuce, onion, leek, carrot and parsley. Foods 9: 680. http://dx.doi.org/10.3390/foods9050680

Hua, J., Fayyaz, A., Song, H., Tufail, M. and Gai, Y., 2019. Development of a method Sin-QuEChERS for the determination of multiple pesticide residues in oilseed samples. Quality Assurance and Safety of Crops \& Foods 11: 511-516. http://dx. doi.org/10.3920/QAS2019.1557

ISIRI, 2010. Institute of standards and industrial research of Iran. Food \& Feed-Maximum limit of heavy metals. No. 12968. Karaj, Iran.

Jacobsen, R.E., Fantke, P. and Trapp, S., 2015. Analysing halflives for pesticide dissipation in plants. SAR and QSAR in Environmental Research 26: 325-342. http://dx.doi.org/10.1080/ 1062936X.2015.1034772

Kang, B., Jyot, G., Sharma, R., Sahoo, S., Battu, R. and Singh, B., 2009. Dissipation kinetics of propargite in brinjal fruits under subtropical conditions of Punjab, India. Bulletin of Environmental Contamination and Toxicology 82: 248-250. http://dx.doi.org/10.1007/s00128-008-9610-7

Khan, B.A., Farid, A., Asi, M.R., Shah, H. and Badshah, A.K., 2009. Determination of residues of trichlorfon and dimethoate on guava using HPLC. Food Chemistry 114: 286-288. http://dx.doi. org/10.1016/j.foodchem.2008.08.092

Kolberg, D.I., Prestes, O.D., Adaime, M.B. and Zanella, R., 2011. Development of a fast multiresidue method for the determination of pesticides in dry samples (wheat grains, flour and bran) using QuEChERS based method and GC-MS. Food Chemistry 125: 1436-1442. http://dx.doi.org/10.1016/j. foodchem.2010.10.041

Kumar, V., Sood, C., Jaggi, S., Ravindranath, S., Bhardwaj, S. and Shanker, A., 2005. Dissipation behavior of propargite--an acaricide residues in soil, apple (Malus pumila) and tea (Camellia sinensis). Chemosphere 58: 837-843. http://dx.doi.org/10.1016/j. chemosphere.2004.06.032

Lazić, S., Šunjka, D., Panić, S., Bjelica, Z. and Vuković, S., 2016. Dissipation rate and residues of acetamiprid and iprodione in sweet cherry fruits. Agrofor 1:143-150. http://dx.doi. org/10.7251/AGRENG1601143L

Lehotay, S.J., Son, K.A., Kwon, H., Koesukwiwat, U., Fu, W., Mastovska, K., Hoh, E. and Leepipatpiboon, N., 2010. Comparison of QuEChERS sample preparation methods for the analysis of pesticide residues in fruits and vegetables. Journal of Chromatography A 1217: 2548-2560. http://dx.doi. org/10.1016/j.chroma.2010.01.044.

Liu, C., Wan, K., Huang, J., Wang, Y. and Wang, F., 2012. Behavior of mixed formulation of metalaxyl and dimethomorph in grape and soil under field conditions. Ecotoxicology and Environmental Safety 84: 112-116. http://dx.doi.org/10.1016/j. ecoenv.2012.06.030

Lou, Z.-Y., Tang, F.-B., Chen, Z.-M., Luo, F.-J. and Liu, G.-M., 2008. Residue and dissipation dynamics of propargite in citrus and soil [J]. Acta Agriculturae Zhejiangensis 4: 282-286.

Malhat, F.M., 2017. Persistence of metalaxyl residues on tomato fruit using high performance liquid chromatography and QuEChERS methodology. Arabian Journal of Chemistry 10: S765-S768. http://dx.doi.org/10.1016/j.arabjc.2012.12.002
Maznah, Z., Halimah, M. and Ismail, B.S., 2018. Evaluation of the persistence and leaching behaviour of thiram fungicide in soil, water and oil palm leaves. Bulletin of Environmental Contamination and Toxicology 100: 677-682. http://dx.doi. org/10.1007/s00128-018-2312-x

Mehri, F., Heshmati, A., Moradi, M. and Khaneghah, A.M., 2019. The concentration and health risk assessment of nitrate in vegetables and fruits samples of Iran. Toxin Reviews 1-8. http://dx. doi.org/10.1080/15569543.2019.1673424

Milinčić, D.D., Vojinović, U.D., Kostić, A.Ž., Pešić, M.B., Trifunović, B.D.Š., Brkić, D.V., Stević, M.Ž., Kojić, M.O. and Stanisavljević, N.S., 2020. In vitro assessment of pesticide residues bioaccessibility in conventionally grown blueberries as affected by complex food matrix. Chemosphere 252:126568. http://dx.doi.org/10.1016/j.chemosphere.2020.126568

Nazemi, F., Khodadadi, I. and Heshmati, A., 2016. Effect of storage type and time and washing methods on dichlorvos residues in tomato. Journal of Mazandaran University of Medical Sciences 26: 36-44.

Omirou, M., Vryzas, Z., Papadopoulou-Mourkidou, E. and Economou, A., 2009. Dissipation rates of iprodione and thiacloprid during tomato production in greenhouse. Food Chemistry 116: 499-504. http://dx.doi.org/10.1016/j.foodchem.2009.03.007

Pallarés, N., Tolosa, J., Gavahian, M., Barba, F.J., MousaviKhaneghah, A. and Ferrer, E., 2020. The potential of pulsed electric fields to reduce pesticides and toxins. In: Pulsed Electric Fields to Obtain Healthier and Sustainable Food for Tomorrow. Elsevier, pp. 141-152.

Ramezani, M.K. and Shahriari, D., 2015. Dissipation behaviour, processing factors and risk assessment for metalaxyl in greenhousegrown cucumber. Pest Management Science 71: 579-583. http:// dx.doi.org/10.1002/ps.3859

Rattan, G. and Sharma, N., 2012. Dissipation kinetics of metalaxyl in cucumber. Bulletin of Environmental Contamination and Toxicology 88: 769-771. http://dx.doi.org/10.1007/ s00128-012-0577-Z

Razzaghi, N., Ziarati, P., Rastegar, H., Shoeibi, S., Amirahmadi, M., Conti, G.O., Ferrante, M., Fakhri, Y. and Khaneghah, A.M., 2018. The concentration and probabilistic health risk assessment of pesticide residues in commercially available olive oils in Iran. Food and Chemical Toxicology 120: 32-40. http://dx.doi. org/10.1016/j.fct.2018.07.002

Serefoglu, C. and Serefoglu, S., 2016. Consumer fair prices for less pesticide in potato. Italian Journal of Food Science 28: 107-120. https://doi.org/10.14674/1120-1770/ijfs.v464

Shin, D., Chae, K., Choi, H., Lee, S., Gim, S., Kwon, G., Lee, H., Song, Y., Kim, K. and Kong, H., 2018. Bioactive and pharmacokinetic characteristics of pre-matured black raspberry, rubus occidentalis. Italian Journal of Food Science 30: 428-439. https:// doi.org/10.14674/IJFS-987

Shoeibi, S., Amirahmadi, M., Rastegar, H., Khosrokhavar, R. and Khaneghah, A.M., 2013. An applicable strategy for improvement recovery in simultaneous analysis of 20 pesticides residue in tea. Journal of Food Science 78: T792-T796. http://dx.doi. org/10.1111/1750-384.1.12100

Szpyrka, E., Kurdziel, A., Matyaszek, A., Podbielska, M., Rupar, J. and Słowik-Borowiec, M., 2015. Evaluation of pesticide residues 
in fruits and vegetables from the region of south-eastern Poland. Food Control 48: 137-142. http://dx.doi.org/10.1016/j. foodcont.2014.05.039

Tandon, S., 2016. Dissipation of pendimethalin in soybean crop under field conditions. Bulletin of Environmental Contamination and Toxicology 96: 694-698. http://dx.doi. org/10.1007/s00128-016-1764-0

Utture, S.C., Banerjee, K., Kolekar, S.S., Dasgupta, S., Oulkar, D.P., Patil, S.H., Wagh, S.S., Adsule, P.G. and Anuse, M.A., 2012. Food safety evaluation of buprofezin, dimethoate and imidacloprid residues in pomegranate. Food Chemistry 131: 787-795. http:// dx.doi.org/10.1016/j.foodchem.2011.09.044.

Varghese, T.S., Mathew, T.B., George, T., Beevi, S.N. and Xavier, G., 2011. Dissipation study of dimethoate, ethion and oxydemeton methyl in chilli. Pesticide Research Journal 23: 68-73.
Waghulde, P., Khatik, M., Patil, V. and Patil, P., 2011. Persistence and dissipation of pesticides in chilly and Okra at North Maharashtra Region. Pesticide Research Journal 23: 23-26.

Webb, S., 2006. Insect Management for Celery and Parsley. Department of Entomology and Nematology Document ENY463, Florida Cooperative Extension Service, Institute of Food and Agricultural Sciences, University of Florida, Gainesville.

Yang, J., Luo, F., Zhou, L., Sun, H., Yu, H., Wang, X., Zhang, X., Yang, M., Lou, Z. and Chen, Z., 2020. Residue reduction and risk evaluation of chlorfenapyr residue in tea planting, tea processing, and tea brewing. Science of the Total Environment 738: 139613. http://dx.doi.org/10.1016/j.scitotenv.2020.139613 